\title{
The effect of plastic deformation on martensite decomposition process in Ti-6Al-4V alloy
}

\author{
Maciej Motyka ${ }^{\mathrm{a}, \mathrm{b},{ }^{*}, \text { Waldemar Ziaja }}{ }^{\mathrm{a}, \mathrm{b}}$, Anna Baran-Sadleja ${ }^{\mathrm{a}, \mathrm{c}}$, Karol Slemp ${ }^{\mathrm{a}}$ \\ a Department of Materials Science, Rzeszow University of Technology, Al. Powstancow Warszawy 12, 35-959 Rzeszow, Poland \\ ${ }^{b}$ R\&D Laboratory for Aerospace Materials, Rzeszow University of Technology, ul. Zwirki i Wigury 4, 35-959 Rzeszow, Poland \\ ${ }^{\mathrm{c}}$ MTU Aero Engines Polska, Tajecina 108, 36-002 Jasionka, Poland \\ *motyka@prz.edu.pl
}

\begin{abstract}
Microstructure and mechanical properties of heat treated martensitic two-phase $\alpha+\beta$ titanium alloys are in major perspective determined by results of martensite decomposition during tempering. The process of martensitic $\alpha^{\prime}\left(\alpha^{\prime \prime}\right)$ phase decomposition in titanium alloys, although utilized in industry for years, has not been sufficiently characterized in the scientific literature. Especially aspects of plastically deformed martensite decomposition is poorly described. Preliminary research results of water quenched Ti-6Al-4V alloy, subsequently cold deformed in compression and tempered at the temperature range of $600-900^{\circ} \mathrm{C}$ for 1 and $2 \mathrm{~h}$ indicated that $\alpha^{\prime}\left(\alpha^{\prime \prime}\right)$ martensite undergoes strain hardening and deformed martensite laths exhibit tendency towards fragmentation and spheroidization during tempering at $900^{\circ} \mathrm{C}$. In the present paper, also $\alpha^{\prime}\left(\alpha^{\prime \prime}\right)$ martensite decomposition under compressive load applied at the temperature range of $600-900^{\circ} \mathrm{C}$ is considered too. Based on light and scanning electron microscopy observations, thermal analyses and XRD measurements, the effect of plastic deformation on kinetics of martensite decomposition and morphology of $\alpha$ phase formed in the process is analysed.
\end{abstract}

\section{Introduction}

Martensitic transformation $\beta \rightarrow \alpha^{\prime}$ ( $\alpha^{\prime \prime}$ ) in titanium alloys occurs during fast, continuous cooling (e.g. water quenching) from the temperature range of stable $\beta$ phase [1,2]. Contrary to martensitic phase in iron-based alloys, the martensitic phase is substitutional supersaturated solid solution and causes less strengthening effect in titanium alloys than martensite in steel [1,3]. Based on the published data [1-5] due to increase of temperature the martensitic metastable $\alpha^{\prime}$ and $\alpha^{\prime \prime}$ phases decompose into a mixture of $\alpha$ and $\beta$ equilibrium phases. It is generally accepted that the efficiency of such decomposition process (tempering) depends on its temperature and time [6]. Quench hardening and tempering operations are usually used for achieving high mechanical properties of two-phase titanium alloys [1,2]. Martensite decomposition is rather rarely considered as a dynamic process, occurring during hot plastic deformation. Results of author's previous investigations [7] on superplasticity in water quench hardened Ti-6Al-4V titanium alloy revealed crucial role of martensite decomposition during following hot working operation in development of equiaxed microstructure. It was assumed that plastic deformation could affect martensite decomposition process in this alloy.

Cold plastic deformation of titanium alloys in hardened state was already analysed [8,9]. It was found among others that deformation of $\alpha$ " phase in Ti-3Al-4.5V-5Mo (VT16) alloy is accompanied by $\alpha " \rightarrow \alpha$ ' laths transformation. In work [9] the process of deformed martensite decomposition in mentioned Ti-3Al-4.5V-5Mo alloy during continuous heating up to $800^{\circ} \mathrm{C}$ was briefly analysed. Hot deformation of martensite in two-phase titanium alloy was analysed in aspects of dynamic recrystallization and ultrafine grained microstructure development $[10,11]$.

An innovative approach adopted in the recent research [12] was to evaluate the effects of cold plastic deformation on martensite decomposition in Ti-6Al-4V alloy. Water quenched alloy was compressed at room temperature and tempered at the temperature range of $600-900^{\circ} \mathrm{C}$. The change of tempered martensite laths' morphology in undeformed and deformed alloy was analysed using microscopy methods. The most significant differences in decomposition processes of undeformed and cold deformed martensite laths were observed after tempering at $900^{\circ} \mathrm{C}-$ deformed laths exhibited tendency towards fragmentation and spheroidization (Fig. 1). The aim of the present paper was to analyse the decomposition process of undeformed martensite under compressive load applied, at the same as before temperature range $\left(600-900^{\circ} \mathrm{C}\right)$. Based on obtained results on decomposition of cold deformed martensite it was intended to evaluate how plastic deformation prior and during tempering influence on martensite decomposition process.

a)

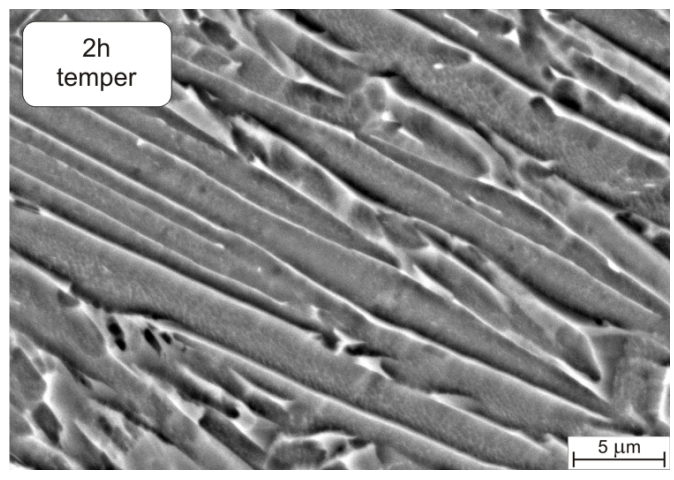

b)

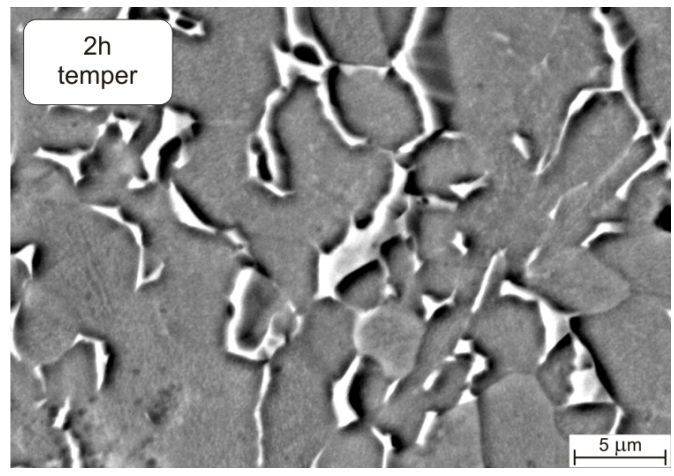

Fig. 1. Microstructure (SEM) of Ti-6Al-4V alloy tempered at $900^{\circ} \mathrm{C}$ for $2 \mathrm{~h}$ after water quenching from the temperature of $1050^{\circ} \mathrm{C}(\mathrm{a})$ and following cold deformation (up to strain of about $20 \%$ ) (b) [12]

(C) The Authors, published by EDP Sciences. This is an open access article distributed under the terms of the Creative Commons Attribution License 4.0 (http://creativecommons.org/licenses/by/4.0/). 


\section{Material and experiments}

Bar with diameter of $8 \mathrm{~mm}$ made of two-phase $\alpha+\beta$ Ti-6Al-4V titanium alloy $(\mathrm{Al}-6.78, \mathrm{~V}-4.38 \mathrm{Fe}-0.18, \mathrm{Si}-0.33$ wt. \% - Ti - balance) was used in the research. Start and finish temperatures of $\alpha+\beta \rightarrow \beta$ phase transformation, previously determined by dilatometric method [3], were 887 and $982^{\circ} \mathrm{C}$ - respectively. Cylindrical samples $(\mathrm{f}=8 \mathrm{~mm}, \mathrm{~h}=10 \mathrm{~mm})$ cut by EDM method were water quenched from the temperature of $1050^{\circ} \mathrm{C}(\mathrm{stable}$ $\beta$ phase range) after 20 min annealing in resistance furnace.

Water quenched samples were deformed at the temperature of 600,750 and $900^{\circ} \mathrm{C}$ in compression tests at the cross-head velocity of 0.1 and 1 $\mathrm{mm} / \mathrm{min}$, using Instron 5982 testing machine. Specimens were air cooled after compression test. The proof stress values were determined from the stress-strain curves (as the extensometer could not be used the strain was calculated based on cross-head displacement).

Light microscope (LM) Leica DMI3000M and scanning electron microscope (SEM) Hitachi S-3400N equipped with EDS detector were employed for microstructural observation. Metallographic specimens were etched using Kroll's reagent. X-ray diffraction (XRD) analysis was performed using ARL X'TRA diffractometer, in $\mathrm{Cu} \mathrm{K} \alpha$ radiation at a voltage of $40 \mathrm{kV}, 2 \theta$ angle range $20-100^{\circ}$ and step size $0,02^{\circ} / 3 \mathrm{~s}$. Vickers hardness in the central zone of longitudinal cross-section of compressed specimens was measured using Innovatest Nexus 4303 tester with test force of $2.942 \mathrm{~N}$.

\section{Results and discussion}

Examined Ti-6Al-4V alloy is characterized by two-phase microstructure composed of larger, elongated a grains and smaller secondary a precipitations in the matrix of $b$ phase (Fig. 2a). Water quenching led to development of fully martensitic microstructure (Fig. 2b).

a)

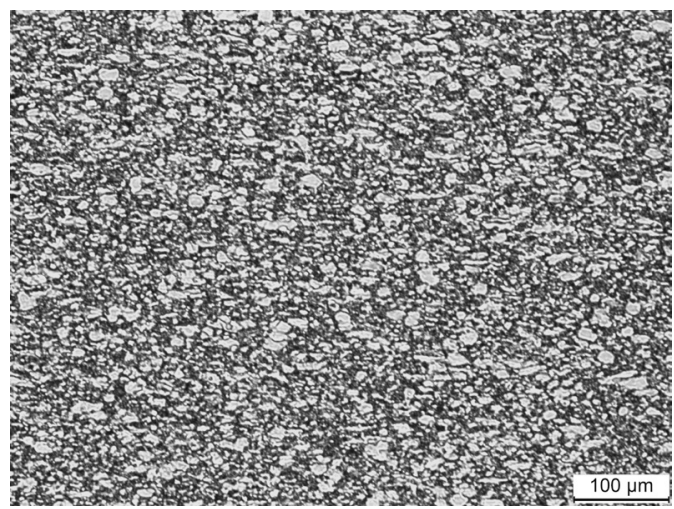

b)

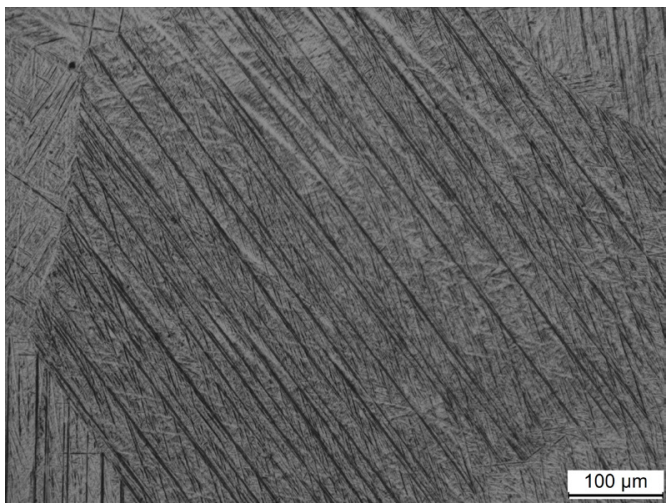

Fig. 2. Microstructure (LM) of Ti-6Al-4V alloy in: a) as-received state (longitudinal cross-section), b) water quenched state (transverse cross-section)

Based on the results of compression tests it was established that both increase of deformation temperature and reduction of strain rate decreased the yield stress of examined alloy (Fig. 3 and Table 1). Yield stress (Table 1) was estimated based on initial diameter of compressed specimens - the highest values were found for the alloy deformed at $600^{\circ} \mathrm{C}-669$ and $717 \mathrm{MPa}$ - whereas the lowest -31 and $66 \mathrm{MPa}$ - for plastic deformation at $900^{\circ} \mathrm{C}$ - with cross-head velocity of 0.1 and $1 \mathrm{~mm} / \mathrm{min}$, respectively.

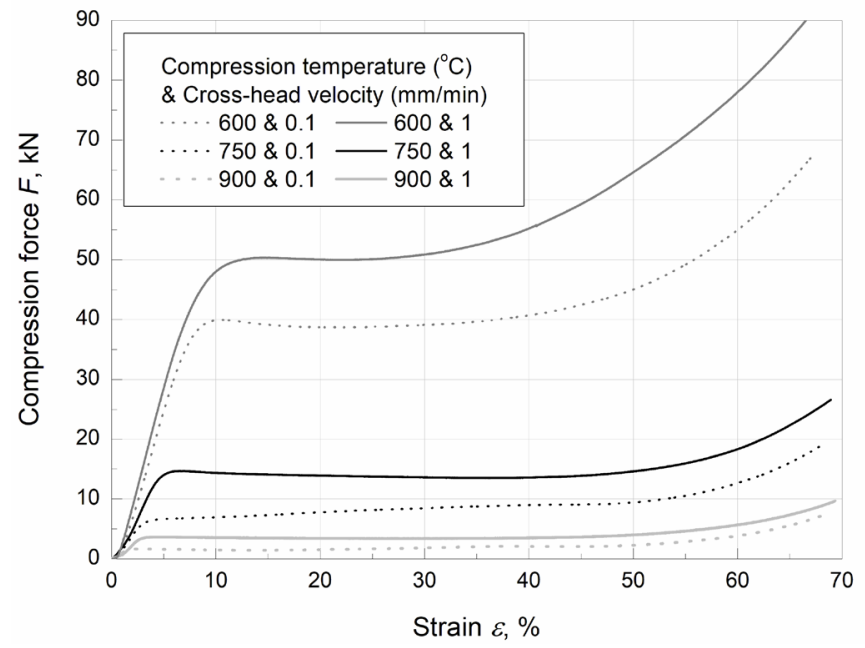

Fig. 3. Hot compression curves of water quenched Ti-6Al-4V alloy 
Table 1. Yield stress* (MPa) of water quenched and hot compressed Ti-6Al-4V alloy

\begin{tabular}{|c|c|c|c|}
\hline \multirow{2}{*}{ Cross-head velocity, $\mathrm{mm} / \mathrm{min}$} & \multicolumn{3}{|c|}{ Compression temperature, ${ }^{\circ} \mathrm{C}$} \\
\cline { 2 - 4 } & 600 & 750 & 900 \\
\hline 0.1 & 669 & 117 & 31 \\
\hline 1 & 717 & 253 & 66 \\
\hline
\end{tabular}

* - calculated for initial specimen's diameter

Compression tests in various conditions caused the formation of high deformation band having about $0.5 \mathrm{~mm}$ width in the central part of specimens - called in the paper "flow localization zone (FLZ) 3 " (Fig. 4). Microstructure in outer parts of compressed specimens - called "undeformed zones [1, - is typical for martensite decomposition in Ti-6Al-4V alloy [12]. No significant changes in martensitic microstructure were detected by light microscopy method after deformation at $600^{\circ} \mathrm{C}$ (Fig. $4 \mathrm{ab}-1$ ). Thickening of $\alpha$ laths was observed after deformation at 750 and $900^{\circ} \mathrm{C}$, especially for lower strain rate (cross-head velocity of $0.1 \mathrm{~mm} / \mathrm{min}$ ) which corresponds to the decomposition time about $1 \mathrm{~h}$ (Fig. $4 \mathrm{c}-\mathrm{d}-1$ ).

In FLZ of specimens tested at $600^{\circ} \mathrm{C}$ very fine-grained microstructure was found (Fig. $4 \mathrm{a}, \mathrm{b}-3$ ). In microstructure in the alloy deformed with the cross-head velocity of $1 \mathrm{~mm} / \mathrm{min}$ some elongated and partially fragmented $\alpha$ laths were detected (Fig. $4 \mathrm{~b}-3$ ). Fragmentation and spheroidization of $\alpha$ laths were also found in FLZ of Ti-6Al-4V alloy compressed at $750^{\circ} \mathrm{C}$ (Fig. $4 \mathrm{c}, \mathrm{d}-3$ ). Dark grains seem to be $\mathrm{b}$ phase. Higher deformation temperature $-900^{\circ} \mathrm{C}$ - caused significant growth of equiaxed $\alpha$ grains formed from martensite laths (Fig. 4e,f - 3 ). It is believed that the grain growth was caused by dynamic recrystallization (DRX) [13] because it is significantly enhanced during deformation with smaller strain rate (Fig. 4e -3 .

Intermediate zones 2 - between FLZ and undeformed zones - are mainly characterized by the presence of highly elongated $\alpha$ laths in matrix of partially fragmented ones (Fig. 4).

a)
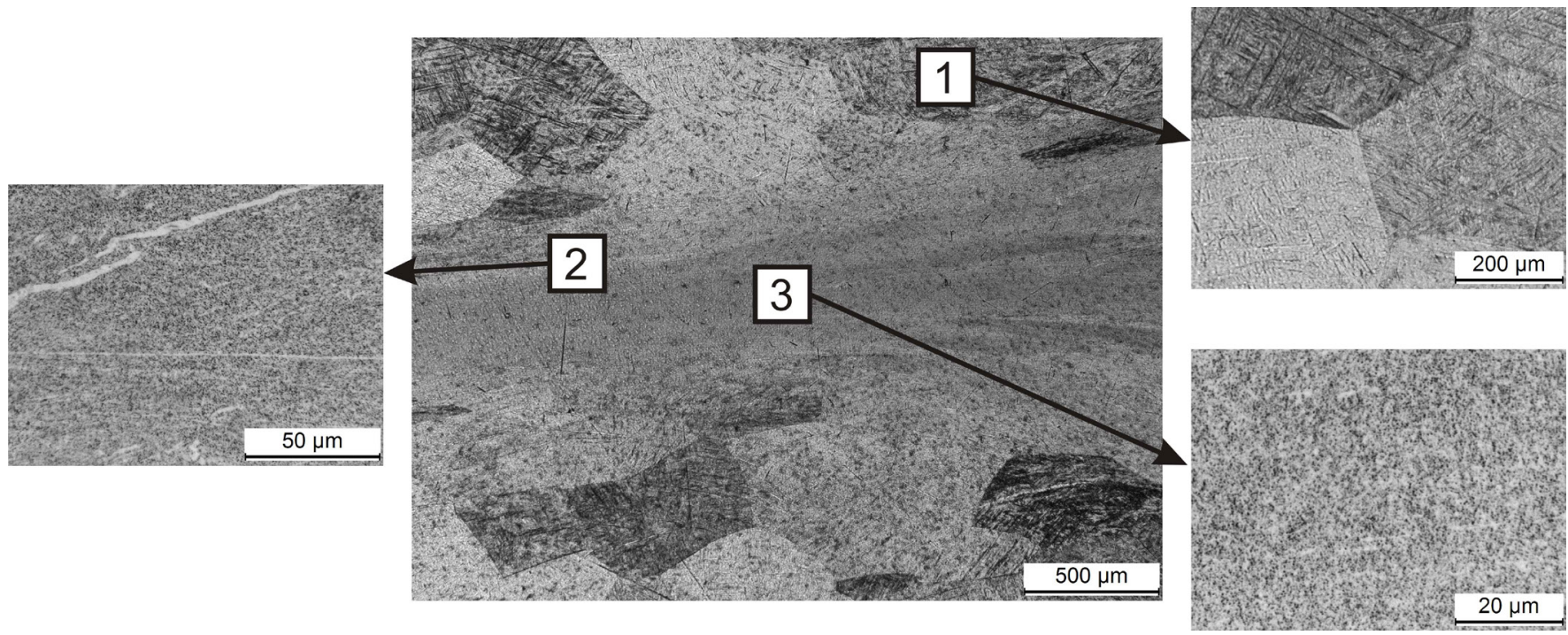

b)
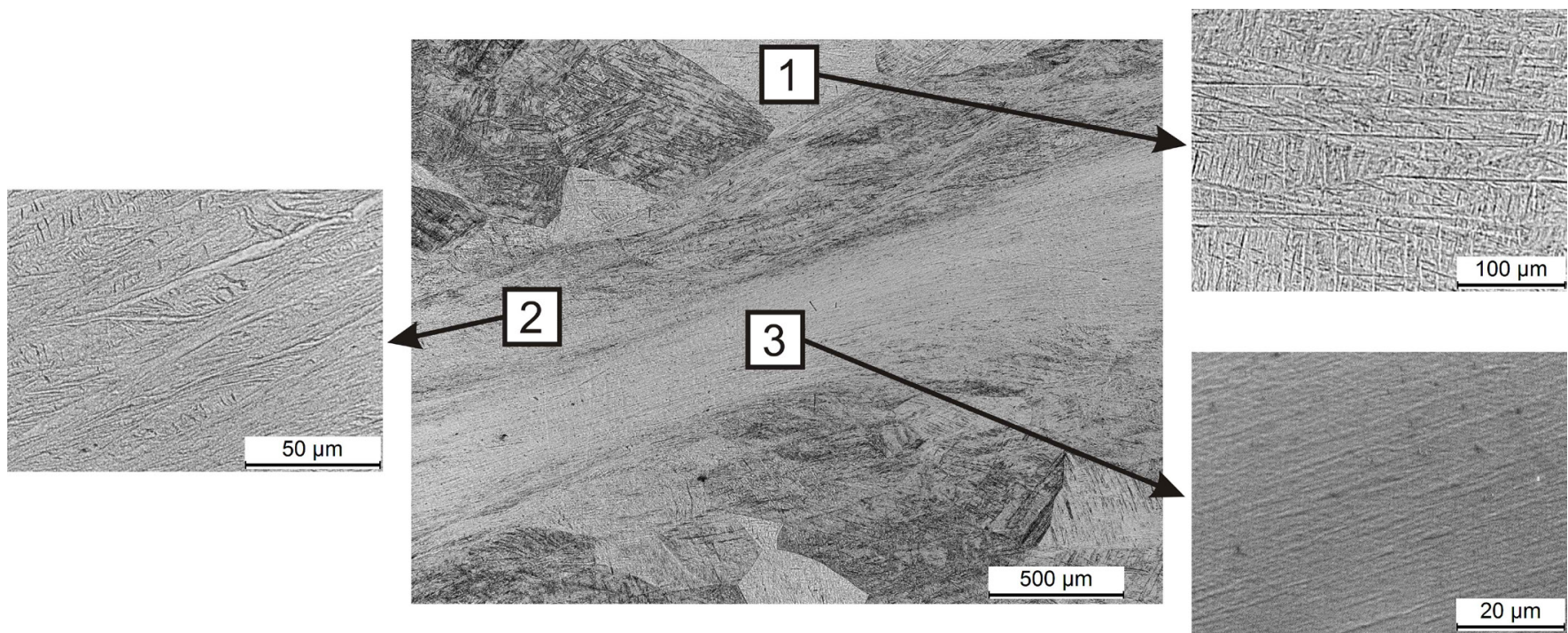


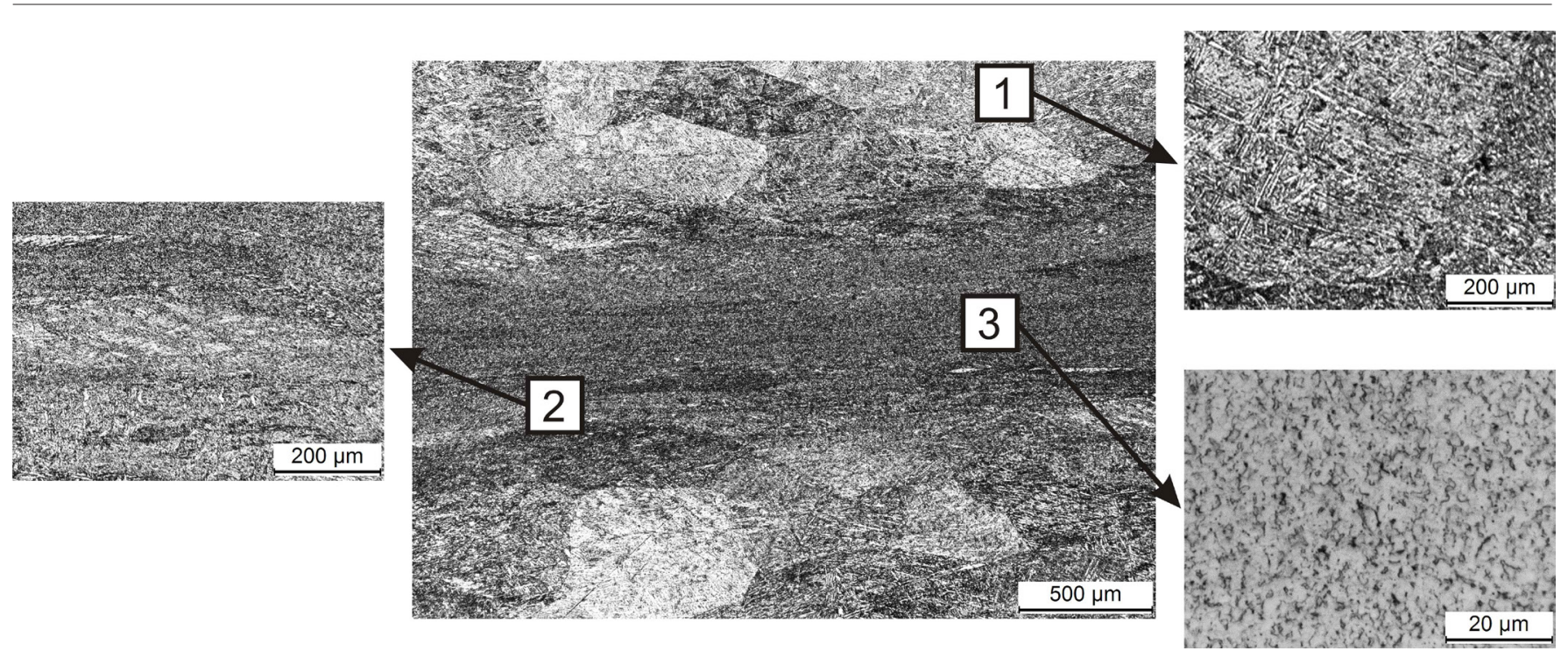

d)
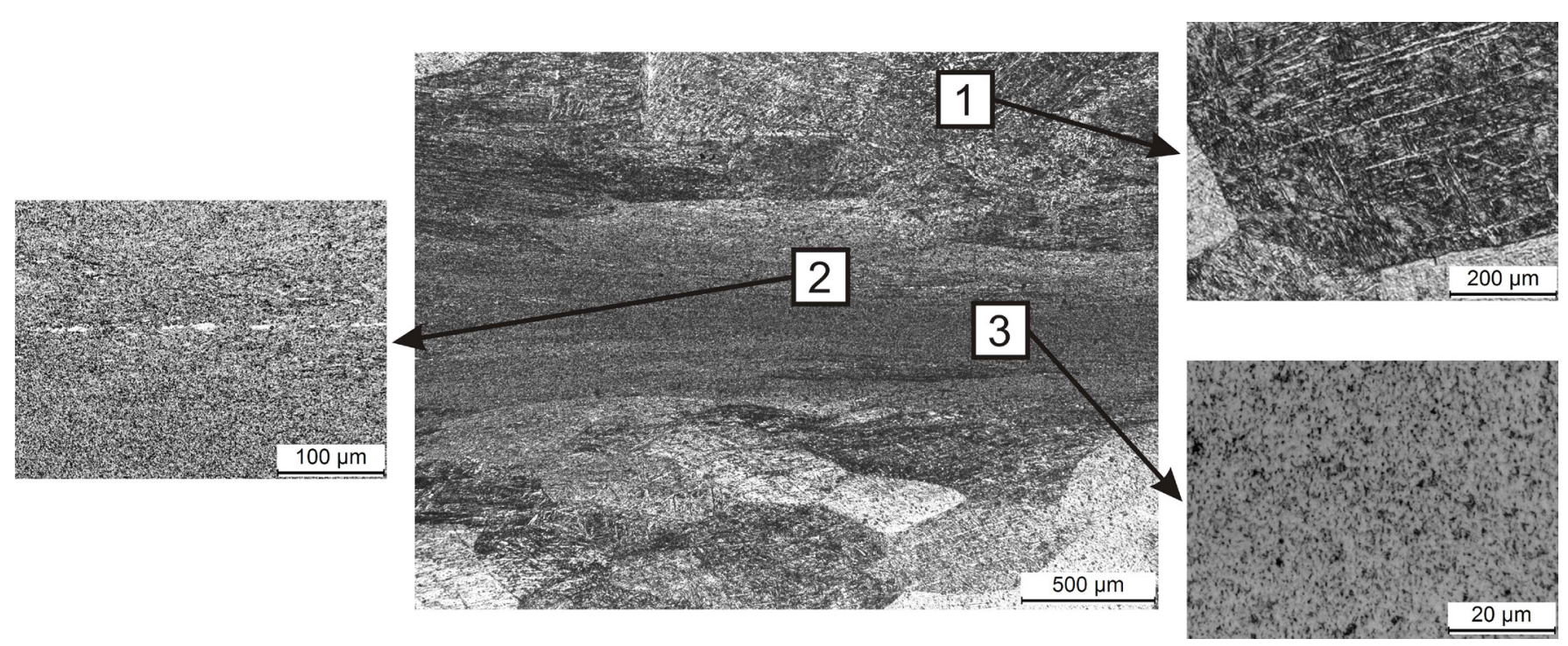

e)
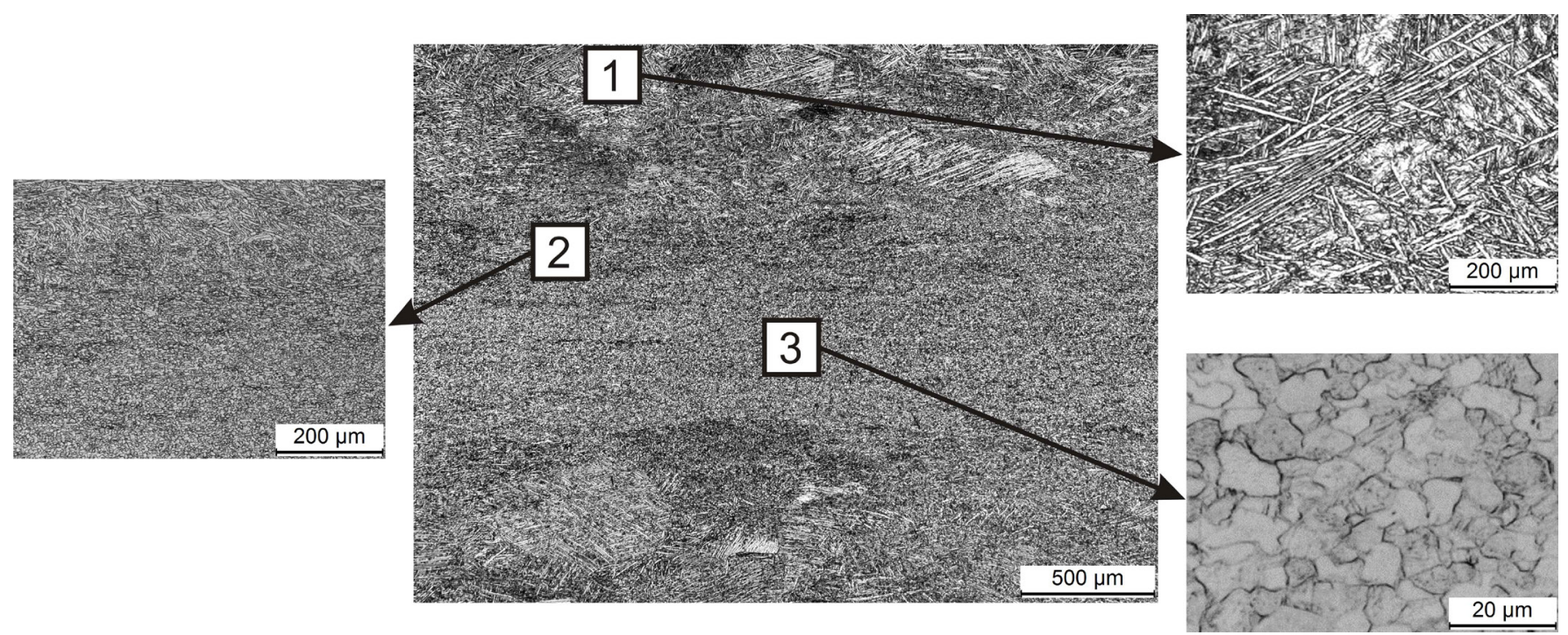


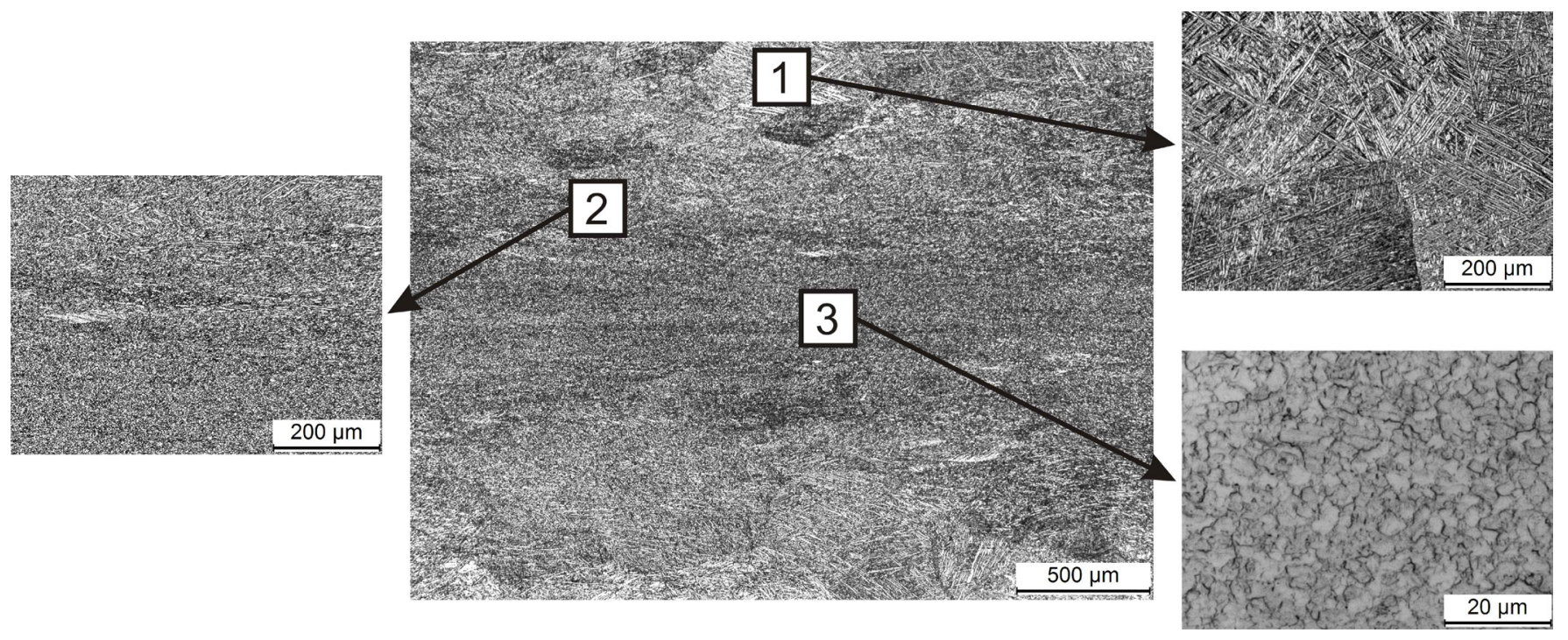

Fig. 4. Microstructure (LM) of water quenched and following hot deformed Ti-6Al-4V alloy at the temperature / cross-head velocity of: 600 / 0.1 (a), 600 / 1 (b), 750 / 0.1 (c), 750 / 1 (d), 900 / 0.1 (e) and $900 / 1$ (f) - ${ }^{\circ} \mathrm{C}$ and mm/min respectively (zones of longitudinal cross-section: 1 - undeformed, 2 - intermediate and 3 - flow localization (FLZ))

More information on microstructure of water quenched and hot deformed Ti-6Al-4V alloy were gathered from SEM observations. It was revealed that microstructure in FLZ of specimens compressed at $600^{\circ} \mathrm{C}$ is ultrafine-grained (UFG) - grain size is significantly smaller than $500 \mathrm{~nm}$ for crosshead velocity of $0.1 \mathrm{~mm} / \mathrm{min}$ (Fig. 5a) and smaller than $200 \mathrm{~nm}$ for $1 \mathrm{~mm} / \mathrm{min}$ (Fig. 5b). Grain refinement in FLZ of specimens compressed at $750^{\circ} \mathrm{C}$ is lower - grain size is higher than $1 \mathrm{~mm}$ (Fig. 5c,d). Deformation of water quenched Ti-6Al-4V alloy at $900^{\circ} \mathrm{C}$ led mainly to growth of $\alpha$ grains formed by decomposition and fragmentation of $\alpha$ ' laths (Fig. 5e,f). Results obtained by SEM method confirmed that DRX was more intense during lower strain rate deformation - typical rectilinear grain boundaries and twins were observed (Fig. 5e).

a)

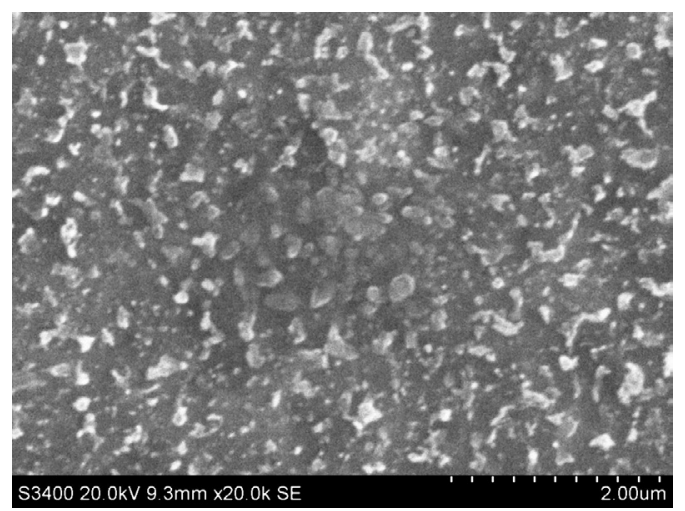

c)

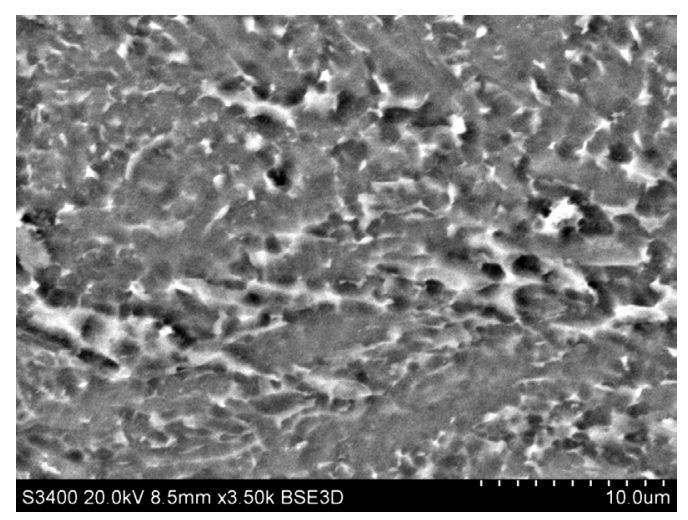

e) b)

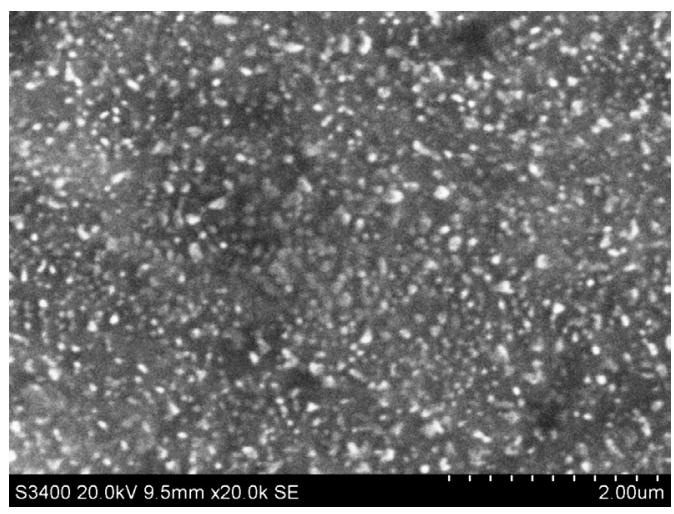

d)

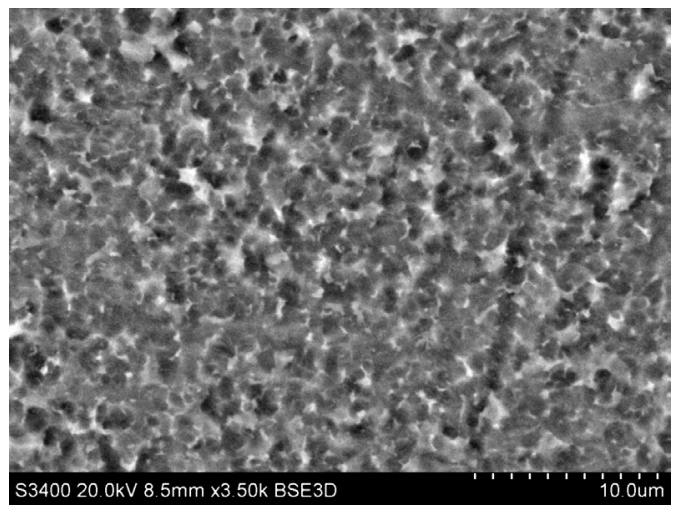

f) 

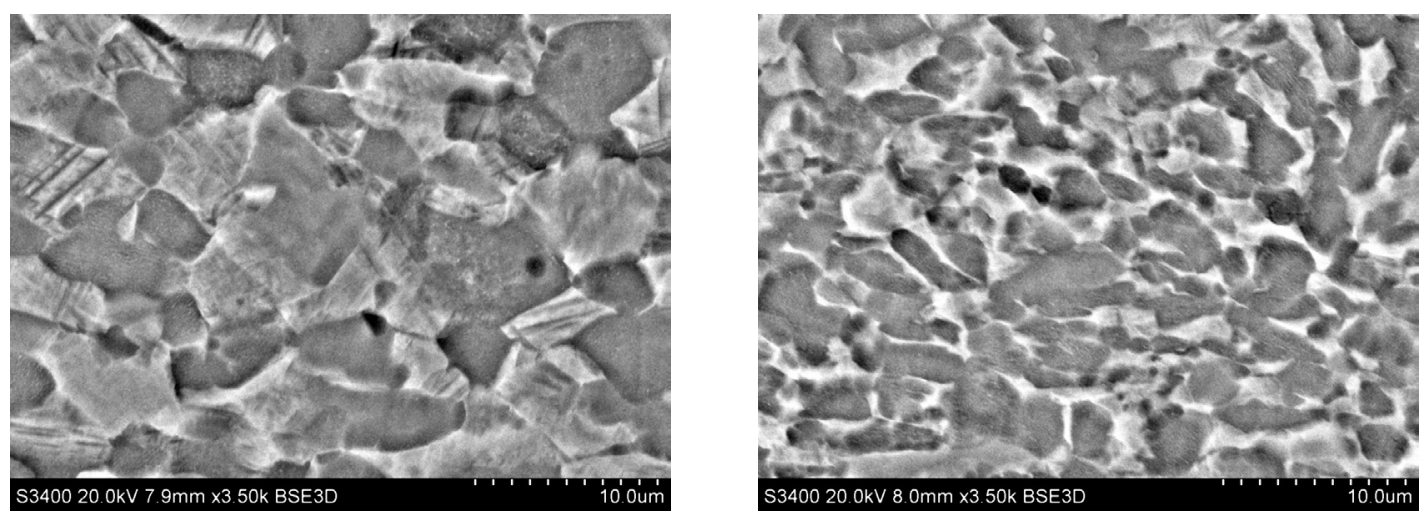

Fig. 5. Microstructure (SEM) of water quenched Ti-6Al-4V alloy and subsequently hot deformed at the temperature / cross-head velocity of: 600 / 0.1 (a), $600 / 1$ (b), 750 / 0.1 (c), $750 / 1$ (d), 900 / 0.1 (e) and $900 / 1$ (f) - ${ }^{\circ} \mathrm{C}$ and mm/min respectively (flow localization zone (FLZ) of longitudinal cross-section)

Performed phase analysis revealed similar types of XRD patterns of water quenched and hot compressed Ti-6Al-4V alloy (Fig. 6a). The intensity of peaks of martensitic a'(a") phase - in water quenched state - is significantly higher comparing with hot deformed state. It should be pointed that in this case XRD measurement was conducted on transverse cross-section whereas deformed alloy was examined on longitudinal cross-section of compressed specimens. It is believed that the product of martensite decomposition in two-phase titanium alloys is a mixture of a and b phases [1-3]. Using XRD method, in previous investigation [12], it was confirmed that $\mathrm{b}$ phase was formed after $1 \mathrm{~h}$ tempering at the temperature range of $600-900^{\circ} \mathrm{C}$. In presented research XRD measurement were conducted in the central part of compressed specimens - in or close to the FLZ. The $b$ phase was detected after deformation at $750^{\circ} \mathrm{C}$ with cross-head velocity of $0.1 \mathrm{~mm} / \mathrm{min}$ (Fig. $6 \mathrm{~b}$ - pattern no 4). It is highly probable that the peak (110) from $\mathrm{b}$ phase for the alloy deformed with cross-head velocity of $1 \mathrm{~mm} / \mathrm{min}$ is overlapped by peaks from a phase (Fig. $6 \mathrm{~b}$ - pattern no 3 ) - its intensity is lower because of much shorter time of martensite decomposition (cross-head velocities of 0.1 and $1 \mathrm{~mm} / \mathrm{min}$ correspond to about $1 \mathrm{~h}$ and 6 min time of deformation, respectively). During deformation at higher temperature $-900^{\circ} \mathrm{C}$ - the DRX process seems to dominate. There is no evidence of $\mathrm{b}$ phase presence (Fig. $6 \mathrm{~b}, \mathrm{c}-$ patterns no 5 and 6 ). Meaningful reduction of intensity of (00.2) and (10.1) peaks at this temperature was found for lower strain rate (Fig. $6 \mathrm{~b}-$ patterns no 5). It indicates the change of texture caused by DRX process.

a)

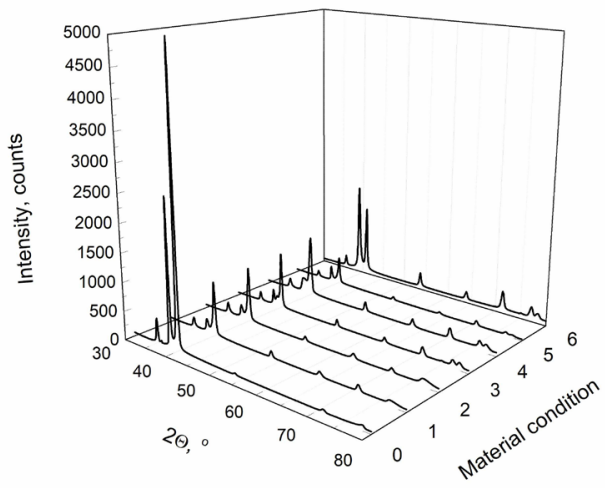

b)

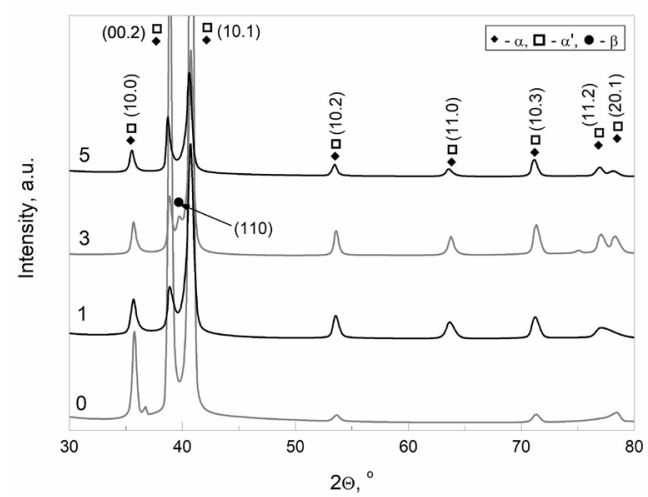

c)

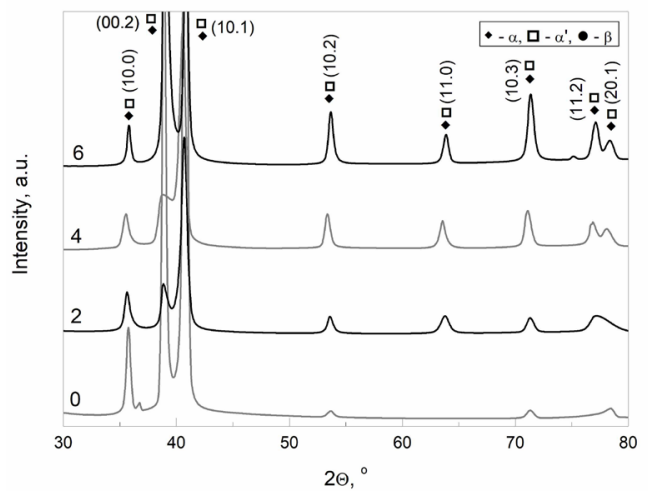

Fig. 6. XRD patterns of Ti-6Al-4V alloy: a) all conditions, b) and c) deformed with lower and higher strain rate respectively (material condition: WQ water quenched, DxVy - deformed at the temperature $x^{\circ} \mathrm{C}$ with the cross-head velocity of $\mathrm{ymm} / \mathrm{min} ; 0$ - WQ, $1-\mathrm{WQ}+\mathrm{D} 600 \mathrm{V0.1}, 2-\mathrm{WQ}+\mathrm{D} 600 \mathrm{~V} 1,3-$ WQ+D750V0.1, 4 - WQ+D750V1, 5 - WQ+D900V0.1, 6 - WQ+D900V1) 
Hardness of water quenched Ti-6Al-4V alloy was about $410 \mathrm{HV}$ (Fig. 7). Deformation at $600^{\circ} \mathrm{C}$ caused increase of hardness up to $440 \mathrm{HV}$ in FLZ of compressed specimens - characterized by UFG microstructure (Fig.5a,b). High value of hardness in undeformed zone for compression with the cross-head velocity of $1 \mathrm{~mm} / \mathrm{min}$ can be caused by short time of martensite decomposition process. The effect of deformation temperature on hardness of water quenched Ti-6Al-4V alloy is not fully clear. Deformation at 750 and $900^{\circ} \mathrm{C}$ led to hardness reduction of the alloy in water quenched state - evaluation of contribution of deformation to this effect needs to further, more detailed analysis.

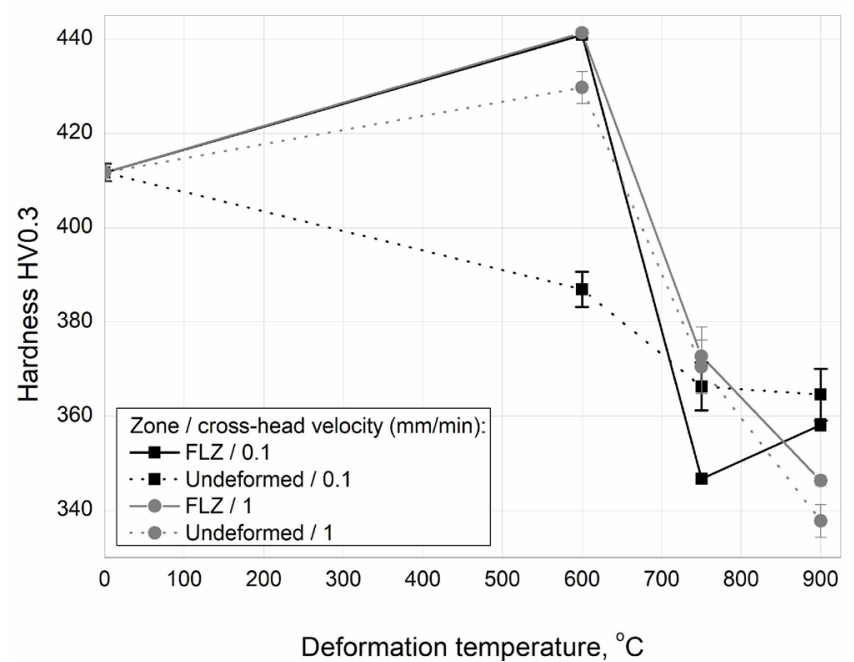

Fig. 7. Hardness of water quenched Ti-6Al-4V alloy and hot compressed - measurements in undeformed and flow localization (FLZ) zones of compressed specimens

\section{Conclusions}

Based on the results of recent studies indicating the effect of cold deformation on martensite decomposition in Ti-6Al-4V alloy further investigation covering hot deformation tests was reported in the paper. Main achievements were described in following conclusions:

1. Compression tests at the temperature range of $600-900^{\circ} \mathrm{C}$ caused the formation of high deformation band having about $0.5 \mathrm{~mm}$ width in the central part of specimens (FLZ).

2. Martensite decomposition in deformed zone of specimens compressed at $600^{\circ} \mathrm{C}$ enhanced a grain refinement. Obtained microstructure is UFG grain size is even smaller than $200 \mathrm{~nm}$ for cross-head velocity of $1 \mathrm{~mm} / \mathrm{min}$.

3. Decomposition of a'(a") phase during deformation at $750^{\circ} \mathrm{C}$ resulted in fragmentation and spheroidization of $\alpha$ laths and seems to be accompanied by $b$ phase formation.

4. Dynamic recrystallization is a dominating process accompanying martensite decomposition during the deformation at $900^{\circ} \mathrm{C}$.

5. Hardness of Ti-6Al-4V alloy having fully martensitic microstructure can be increased by deformation at $600^{\circ} \mathrm{C}$ and at the high strain rate.

\section{References}

[1] A. Bylica, J. Sieniawski, Tytan i jego stopy. PWN, Warsaw 1985.

[2] G. Lutjering, J.C. Williams, Titanium. Springer-Verlag, Berlin Heidelberg 2003.

[3] M. Motyka, Proces cieplno-plastyczny ksztaltowania morfologii skladnikow fazowych mikrostruktury oraz plastycznosci dwufazowych stopow tytanu. RUT Press, Rzeszow 2015.

[4] Y. Mantani , M. Tajima M, Mater. Sci. Eng. A438-440 (2006) 315-319.

[5] K. Sato, H. Matsumoto, K. Kodaira, T.J. Konno, A. Chiba, J. Alloy Comp. 506 (2010) 607-614.

[6] F.X. Gil Mur, D. Rodríguez, J.A. Planell, J. Alloy Comp. 234 (1996) 287-289.

[7] M. Motyka, J. Sieniawski, W. Ziaja, Mater. Sci. Eng. A599 (2014) 57-63.

[8] X. Li, M. Sha, J. Chu, Metal. Sci. Heat Treat. 51 (2009) 594-598.

[9] A.G. Illarionov, S.L. Demakov, S.I. Stepanov, S.M. Illarionova, Phys. Metals Metallography 116 (2015) 267-273.

[10] J.L. Gu, X.J. Sun, B.Z. Bai, N.P. Chen, Mater. Sci. Tech. 17 (2001) 1516-1524.

[11] Q. Chao, P.D. Hodgson, H. Beladi, Mater. Sci. Forum. 783-786 (2014) 679-684. 
[12] M. Motyka, A. Baran-Sadleja, J. Sieniawski, M Wierzbinska, K Gancarczyk, Mater. Sci. Tech. 35 (2019) 260-272.

[13] S. Zherebtsov, M. Murzinova, G. Salishchev, S.L. Semiatin, Acta Mater. 59 (2011) 4138-4150. 